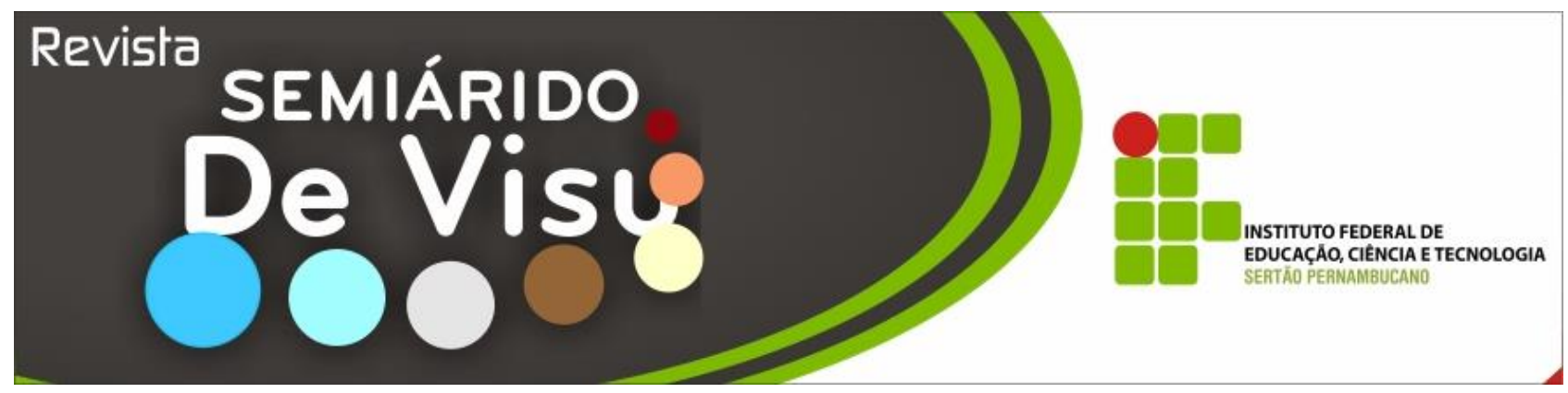

\title{
Viabilidade do uso de água residuária na agricultura familiar
}

\author{
Jorge Messias Leal do Nascimento ${ }^{1}$, Priscila da Silva Lacchine ${ }^{2}$, Wallace Luís de Lima ${ }^{3}$, Mário \\ Adriano Ávila Queiroz ${ }^{4}$ \\ ${ }^{1}$ Faculdade São Francisco de Juazeiro - FASJ, Juazeiro-BA, Brasil. * e-mail: jorge_messias@ymail.com \\ ${ }^{2,3}$ Instituto Federal de Educação, Ciência e Tecnologia do Espírito Santo - IFES, Campus de Alegre - Espirito Santo, Brasil. \\ ${ }^{4}$ Universidade Federal do Vale do São Francisco - UNIVASF, Petrolina - PE, Brasil; e-mail: mario.queiroz@ univasf.edu.br
}

\begin{abstract}
RESUMO: Nessa revisão, abordamos discussões sobre a viabilidade do uso da água residuária da produção de bovinos e suínos para a produção pastagens na agricultura familiar. Assim, o desenvolvimento de práticas de reutilização das águas residuárias provenientes do processo produtivo de por cultivos agrícolas, como as pastagens, permitirá a obtenção de benefícios ambientais tais como a minimização da poluição hídrica, redução e controle do consumo de água limpa por meio da fertirrigação. Foi realizado um estudo bibliográfico que reúne informações técnicas e econômicas para implantação de dispositivos de controles ambientais, como o Sistema de Tratamento de Efluente e Dejetos (STED), em pequenas propriedades, que agrega valor aos resíduos. A fertirrigação de pastagens, com água residuária das atividades da bovinocultura leiteira e suinocultura, tem se mostrado um método eficaz e que acarreta em benefícios para o agricultor, para o animal, para o solo e para a produção vegetal. No entanto, é importante destacar que, projetos de fertirrigação devem seguir diretrizes e procedimentos técnicos para garantir sua eficiência e seus efeitos benéficos para o meio ambiente.
\end{abstract}

Palavras-chave: fertirrigação de pastagens, resíduos líquidos, recuperação hídrica, tratamento de dejetos

\section{Viability and use of wastewater in agriculture family}

\begin{abstract}
In this review, we addressed issues that permeate discussions related the use of wastewater from the production of cattle and pigs on family farms. Thus, the development of practices for the reuse of wastewater from the production process for agricultural crops such as pastures, provides environmental benefits. For example, minimizing water pollution, reducing and control of clean water consumption through fertirrigation. In this context, we carried out a literature review that brings together economic and technical information for implementation of environmental control devices, such as Effluent and Waste Treatment System (STED) in small properties adding value to waste. Fertirrigation of pasture with wastewater from swine and cattle raising activities have been shown to be an effective method which results in benefits to the farmer, for the animal, to the soil, and to crop production. However, it is important that fertirrigation projects should follow guidelines and technical procedures to ensure its efficiency and its beneficial effects to the environment.
\end{abstract}

keywords: pasture of fertirrigation, wastewater, Water recovery, waste treatment 


\section{Introdução}

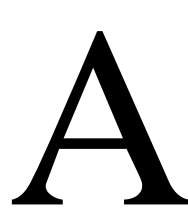

Bovinocultura leiteira

Suinocultura constituem as

principais atividades agropecuárias que alavancam o setor do Agronegócio Brasileiro. Este fato é atribuído ao quantitativo animal, logo, o Brasil ocupa o terceiro lugar no ranking para produção de leite, sendo responsável por mais de 32 milhões de litros produzidos (MAPA, 2011). Para a Suinocultura, o Brasil é responsável pelo significativo volume $(600 \mathrm{mil} / \mathrm{ton})$ de carne exportada, sendo os principais centros consumidores, a Rússia, Ucrânia, África do Sul e Hong Kong (ABIPECS, 2013).

Diante deste cenário econômico, torna-se imperativo considerar a elevada produção de efluentes líquidos oriundos dessas atividades, logo, os mesmos poderão ocasionar impactos ao meio ambiente se manejados de forma inadequada.

Com isso, ressalta-se que, a água constitui recurso natural limitado, sendo necessária buscas de alternativas que otimizem a sua utilização. Para isso, é necessária à realização de pesquisas direcionadas à reutilização dos efluentes líquidos gerados por meio da Bovinocultura leiteira e Suinocultura, principalmente, devido à viabilidade financeira e os benefícios ambientais advindos de sua correta utilização (MIRANDA, 2005).

Nesse sentido, a aplicação dos efluentes líquidos gerados por meio dessas atividades agropecuárias poderá beneficiar a produção agrícola, logo, os mesmos constituem em fontes de nutrientes, os quais são necessários à nutrição vegetal. Desta forma, sugere-se que, essa tática de manejo permitirá redução da aplicação de fertilizantes sintéticos na produção agrícola, resultando em menor impacto do meio ambiente, além de proporcionar produção vegetal com tendência à sustentabilidade ambiental (HERNANDES, 2010; SEGANFREDO, 2010).

Com base nesse contexto, objetivou-se realizar um compêndio de informações a respeito da viabilidade de reuso dos efluentes líquidos oriundos da Bovinocultura leiteira e
Suinocultura na produção e manutenção de pastagens no âmbito da agricultura familiar.

\section{Revisão de Literatura}

Uso da água, geração e tratamentos de efluentes da Bovinocultura leiteira e da Suinocultura

A exigência de água para a sobrevivência dos seres humanos e produção animal apresentam similaridade no que tange à qualidade e quantidade. Em ambos, o fornecimento da água constitui fator primordial para o conforto e bem estar, contudo, os elevados consumos de água pela agropecuária, sem a devida gestão da mesma, têm ocasionado redução da sua fração potável (BELLAVER \& OLIVEIRA, 2009).

Para à Bovinocultura leiteira, à agua constitui recurso essencial para sobrevivência e realização das atividades de manejos, a exemplos: processos de higienização dos animais, limpeza dos equipamentos de ordenha e armazenamento do leite (PICININ, 2010). Este fato é corroborado por Viana (2009), que reporta que o consumo médio de água por unidade animal (bovinos), pode alcançar até 120 L/animal adulto ao dia, além disso, relatam que esse, inserido nesse volume insere-se as necessidades de realização das atividades de limpeza de equipamentos e instalações.

Campos (2000) afirma que vacas em lactação apresenta necessidade de ingestão diária de 62,5 L de água, enquanto que Guerra et al. (2011) reportam segundo a CCPR-MG (2004) valores da ordem de 100 L de água por vaca/ordenha, demonstrando assim, o grande volume de água que é exigido por esses animais para que possam expressar o seu potencial produtivo. Essa informação correlaciona-se com a composição química do leite, que constitui de aproximadamente $87 \%$ de água, consequentemente redução da água limitará consideravelmente a produção de Bovinos leiteiros (LAGGER et al., 2000), podendo resultar perdas econômicas significativas para o setor do agronegócio Brasileiro.

De modo similar aplica-se à Suinocultura, logo a água constitui para esses animais parte da 
sua alimentação, além de representar uma das alternativas que auxiliam no mecanismo de controle térmico frente aos processos termorregulatórios, sendo requerido por esses animais quantidades médias variando de 3,0 à 30,5 L de água por unidade animal ao dia a depender da categoria (PERDOMO et al., 2003).

Outro aspecto relevante ao assunto faz menção ao conhecimento da quantidade $\mathrm{e}$ qualidade da água ingerida pelos animais de produção, logo, isto poderá refletir no desempenho e estado sanitário dos mesmos (PALHARES, 2010).

Em relação ao estado sanitário dos animais, Serafim \& Galbiatte (2010) afirma que, as gerações de efluentes líquidos oriundos da limpeza das instalações, perdas através do consumo animal juntamente com a produção de dejetos devem receber tratamento adequando, tendo em vista que, constituem fatores complicadores da produção animal e podem influenciar a sanidade dos animais.

O Conselho Nacional do Meio Ambiente (CONAMA) criou no ano de 2005 a resolução 357, retratando os parâmetros que conferem a qualidade de águas superficiais, sabendo-se que, as mesmas são utilizadas pelos animais. Embora essa resolução disponha sobre a classificação dos corpos de água e diretrizes ambientais para esse enquadramento, há restrição na mesma apenas às águas superficiais, entendendo este aspecto e vislumbrando a real situação dos produtores do setor da agricultura familiar, que dispõe em sua maioria sobre fontes de águas subterrâneas, o CONAMA elaborou a resolução 396 no ano de 2008, que trata dos enquadramentos e diretrizes para águas subterrâneas e dá outras providências.

Com isso, têm-se que, as perspectivas e diretrizes para o desenvolvimento rural com tendência a sustentabilidade ambiental dirigemse à implementação de medidas que integre as comunidades locais, difundindo os resultados de pesquisas realizadas sobre a situação econômica, social e ambiental, promovendo assim intervenções, seja na ordem de assistência técnica ou das decisões sobre políticas públicas necessárias à promoção deste desenvolvimento (GEBLER \& PALHARES, 2007).
A partir desse contexto, podemos citar o Programa Nacional para Fortalecimento da Agricultura Familiar criado no ano de 1996 (SCHNEIDER, 2003). Vale destacar que, esse programa é constituído por pequenos e médios produtores, representando a maioria dos produtores rurais do Brasil (PORTUGAL, 2004), além disso, a lei 11.326 de 2006 fundamenta sobre os requisitos integradores da agricultura familiar (BRASIL, 2006).

No cenário do estado do Espirito Santo, Brasil, constata-se a existência de 67.403 estabelecimentos de agricultura familiar com base na lei 11.326 de 2006, perfazendo um total de $80 \%$ dos estabelecimentos agrícolas do referido estado, entretanto, os mesmos representam apenas $34 \%$ da área total, em hectare dos estabelecimentos agropecuários do estado. Para a Bovinocultura leiteira e Suinocultura constata-se 12.661 e 15.242 estabelecimentos no estado supracitado, respectivamente (FRANÇA et al., 2009).

Diante desse efetivo animal, da demanda dos consumidores por proteína de origem animal é imprescindível afirmar que, os sistemas de produção animal no estado do Espirito Santo têm sido de forma intensiva, devido à topografia acidentada ocorrente neste estado, além disso, constata-se ausência de controle ambiental relacionado ao destino e tratamento dos dejetos e resíduos oriundos das atividades de manejos aplicados nessas atividades agropecuárias (ASSENHEIMER, 2007), podendo desta forma, oferecer riscos de contaminação ao meio ambiente e à saúde da população como também comprometer a sanidade dos próprios animais (PERDOMO et al., 2001; CAMPOS et al., 2002).

Nesse contexto, a Suinocultura destaca-se em relação à Bovinocultura leiteira, logo, a mesma é reconhecida como atividade de potencial impacto poluidor do meio ambiente, seja do solo ou das fontes de águas, devido às cargas poluentes que são perdidas, como exemplos: fósforo, nitrogênio, matéria orgânica, sedimentos, metais pesados, hormônios e antibióticos presentes nas rações (CORRÊA et al., 2008).

Segundo Campos et al. (2002), os impactos ambientais podem ser maiores quando 
a contaminação ocorre nos cursos de água em relação ao solo, pois os resíduos oriundos dessa atividade apresentam alta demanda bioquímica de oxigênio, reduzindo o teor desse elemento nas fontes de água, além de causar a eutrofização dos mesmos, proporcionando o crescimento desordenado de plantas aquáticas (FURTADO, 2007).

Para a Bovinocultura, Rodrigues et al. (2008) reportam que nos dejetos de novilhos foram constatados de 46-76 g/animal/dia de nitrogênio, 40-105 g/animal/dia de potássio e 9,2-11,2 $\mathrm{g} / \mathrm{animal} / \mathrm{dia}$ de fósforo. Desta forma, podemos sugerir que, esses dejetos podem ser utilizados na forma de biofertilizantes, substituindo assim, a aplicação de fertilizantes sintéticos, reduzindo desta forma os custos nas aquisições destes na produção vegetal.

Desta forma, o uso dos biofertilizantes deve ser realizado com cautela, haja vista a possibilidade de contaminação do solo, embora a sua aplicação em doses baixas, proporcione incrementos de produtividades e rendimento das plantas (SCHEFFER-BASSO et al., 2008).

Nesse sentido, recomenda-se a adoção de sistemas de tratamentos dos dejetos e efluentes líquidos adaptados à realidade de cada propriedade rural e que estejam fundamentados na legislação ambiental, possibilitando dessa forma redução da contaminação ambiental. Nesse caso, aplica-se a elaboração de projeto de fertirrigação, que deve ser condizentes com as leis Federais 9.605 de 1998, 4.771 de 1965 e 6.938 de 1981.

Dentre as alternativas cabíveis ao fator econômico dos pequenos e médios produtores rurais, têm-se o armazenamento dos dejetos em lagoas de estabilizações e biodigestores. O emprego das lagoas de estabilização consagrouse no tratamento de efluente, pois além do baixo custo de implantação e manutenção, mostra-se muito eficaz na remoção da matéria orgânica (DIAS et al., 2006), reduzindo a poluição do solo e da água causada pelos efluentes rurais. $\mathrm{O}$ uso de biodigestores nos sistemas de produção animal é visto como uma ferramenta importante, pois estes promovem o tratamento do resíduo e retornam parte da energia que seria perdida, de volta ao sistema produtivo, através da queima do gás (ORRICO et al., 2007).
Em sequência Kunz et al. (2004) reportaram que o custo para construção de uma esterqueira de alvenaria com capacidade para $100 \mathrm{~m}^{3}$ é de aproximadamente $\$ 7.000,00$ reais.

Outra opção são os biodigestores, que possibilita a agregação de valor ao resíduo tratado pelo crédito do carbono, mediante a utilização do biogás produzido em sistema de geração de energia, além do biofetilizante, que pode posteriormente ser utilizado na fertirrigação das pastagens, resultando em produção de alimentos para bovinos e suínos a partir dos próprios resíduos gerados pelos mesmos (PERDOMO et al., 2003). Estudos têm demostrado a existência de pequenos e médios produtores fazendo uso dos mesmos, devido à lucratividade associada à agregação de valor, mesmo existindo custo inicial alto de implantação desse sistema em torno de \$ $16.000,00$ reais para um biodigestor tubular de PVC com capacidade de $25 \mathrm{~m}^{3}$ (Silva, 2009).

No caso da Bovinocultura leiteira, estudo realizado por Silva \& Roston (2010) reporta que, a utilização de lagoa de estabilização apresenta potencial de aplicação nos tratamentos dos efluentes gerados a partir dessa atividade. De modo similar, Araújo et al. (2012) também constataram para a Suinocultura, melhores benefícios da utilização de lagoas de estabilização no tratamento de dejetos e efluentes visando a sua utilização futura, sendo essa alternativa de uso frequente pelos pequenos e médios produtores, fato atribuído ao custo de implantação (POHLMANN et al., 2009), que segundo Jasper (2006) dependendo do número de animais a construção de lagoas de estabilização pode variar entre $\$ 15.000,00 \mathrm{a}$ $150.000,00$ reais para 100 e 1000 animais, respectivamente.

O equalizador constitui outra opção de tratamentos de efluentes na agricultura familiar, logo promove a homogeneização do resíduo provindo do processo produtivo permitindo o controle da vazão e redução de custos de investimentos e operação. Em relação aos custos de implantação Oliveira (2006) afirma que o custo de referência é de $\$ 100,00 / \mathrm{m}^{3}$ construído. Por outro lado, os decantadores constituem também em alternativa no tratamento de efluentes, possibilitando a separação das fases 
líquidas e sólidas dos dejetos, sendo que a parte sólida deve ser direcionada para a esterqueira e posteriormente utilizada como fertilizante orgânico e a parte líquida para lagoas de tratamentos, visando à remoção dos efluentes e posteriores aplicações na fertirrigação (KUNZ et al., 2010; FRICK, 2011). Além disso, os custos de implantação são da ordem de \$ 150,00/ $\mathrm{m}^{3}$ construído (OLIVEIRA, 2006).

\section{Produção de Pastagem com reutilização de água residuária em fertirrigação}

A reutilização da água, não é um conceito atual e há muitos anos tem sido praticado, contudo, devido à escassez deste recurso natural e a crescente demanda pela mesma, práticas de reutilização da água têm se tornado tema atual e de grande importância (FRONZA, 2004). Desta forma, manejos de uso racional da água com menor impacto ambiental decorrente da produção de efluentes, devem ser buscados (SEGANFREDO, 2010).

Embora não exista base de dados estatísticos oficiais que demonstrem o significativo aumento das áreas sobre cultivo fertirrigado no Brasil, as evidências de que essa técnica teve um avanço considerável na última década é indiscutível (SILVA, 2010), porém, o aumento do uso da fertirrigação no Brasil e no mundo, ocorreu devido à mesma ter se mostrada efetiva em relação ao aumento da produtividade e rendimento, consequentemente, no lucro obtido pelos produtores (VILAS BÔAS \& SOUZA, 2008). Nesse sentido, Papadopoulos (1993) afirma que, em países com nível de produtividade elevado, a fertirrigação tem sido recomendada, logo, a mesma promove aumento na eficiência de aproveitamento de nutrientes pelas culturas agrícolas com diminuição da contaminação dos mananciais pelo descarte inadequado dos efluentes líquidos, além de possibilitar redução da deficiência hídrica pelas plantas em regiões áridas e semiáridas.

Por outro lado, à aplicação da fertirrigação na produção de pastagens poderá minimizar as perdas em fitomassa vegetal como também os custos de manutenção do pasto (SCHEFFERBASSO et al., 2008), haja visto que, a deficiência hídrica implica em perdas econômicas devido à redução das taxas fotossintéticas (TAIZ \&ZEIGER, 2004), e no caso da aplicação da fertirrigação, soma-se á alocação de nutrientes e água à cultura de interesse.

Desta forma, a fertirrigação advinda de fontes orgânicas, e essas últimas obtidas por meio de tratamentos de dejetos e efluentes líquidos da Bovinocultura leiteira e Suinocultura, surgem como estratégia econômica, pois possibilita a reciclagem de nutrientes da alimentação animal para a produção de fitomassa vegetal, além de promover melhorias às condições físicas, químicas e biológicas do solo, contribuindo assim, para manutenção de um sistema produtivo equilibrado com tendência à sustentabilidade ambiental (CAMPOS, 2008; SANTOS et al., 2012).

Nesse sentido, regiões onde a temperatura não constitui fator limitante para a produção de pastagem, a fertirrigação representa alternativa promissora para o suprimento de nutrientes e água às plantas, logo, a demanda por produtos de origem animal exige altas produções de fitomassa vegetal destinada à alimentação dos animais, possibilitando aumento na produção de alimentos com base na nutrição orgânica das plantas, como demostrado por Menezes et al. (2009), sendo constatados que à aplicação de $150 \mathrm{~m}^{3} /$ ha de dejetos líquidos de suínos resultou em incrementos na produção de biomassa seca aérea de plantas de Brachiaria brizantha (Hochst) Stapf cv. Marandu (5,73 ton/ha) e Cynodun dactylon Pers. (8,07 ton/ha) enquanto o tratamento sem adubação apresentou 3,77 e 5,44 ton/ha, respectivamente para essas forrageiras. Em seguida Serafim \& Galbiatti (2010) avaliando o efeito do uso de água residuária da Suinocultura na produção de fitomassa de Brachiaria brizantha (Hochst) Stapf cv. Marandu (CIAT 6294 - IRI 822 - BRA 000591) constataram que a dose de $600 \mathrm{~m}^{3}$ proporcionou maior valor médio de $69,56 \mathrm{~kg}$ MS ha ${ }^{-1} \mathrm{dia}^{-1}$, demonstrando assim, o potencial que os efluentes das atividades agropecuárias apresentam em serem reutilizados na produção de pastagem.

\section{Conclusões}


A chamada agricultura familiar, no Brasil, vem se redesenhando e mostrando peça fundamental para o desenvolvimento agrícola do país. Entretanto, promover o uso integral e racional dos recursos disponíveis dentro da propriedade ainda é um desafio para agricultores e pesquisadores, para que isso ocorra, é necessário aumentar a eficiência do sistema de produção, reduzindo os custos e maximizando a produtividade em busca de sistemas sustentáveis de produção.

O aumento no desenvolvimento de atividades ligadas a Suinocultura e Bovinocultura leiteira, em sistemas familiares, devido à facilidade no manejo e na aceitação comercial, houve um acréscimo significativo nos impactos ambientais decorrente de ambas as atividades.

Os dispositivos de controles visam melhorias e adequação dos rejeitos oriundos da produção animal, para a sua utilização como biofertilizante, dentro da propriedade de acordo com as legislações ambientais vigentes. A utilização desses biofertilizantes na fertirrigação de pastagens pode ser a solução para resolver a demanda de nutrientes do sistema e também da necessidade hídrica na produção vegetal.

Dessa forma é importante que os agroecossistemas familiares adotem técnicas mais sustentáveis no desenvolvimento de práticas agrícolas, incorporando essas medidas aos princípios de uma nova proposta de desenvolvimento, que priorize a maximização da produção e a diminuição do uso de insumos externos, e consequentemente, promovam melhorias no ambiente natural.

\section{Referências}

ARAÚJO, I.S.; OLIVEIRA, J.L.R.; ALVES, R.G.C.M.; BELI-FILHO, P.; COSTA, R.H.R. Avaliação de sistema de tratamento de dejetos suínos instalado no Estado de Santa Catarina. Revista Brasileira de Engenharia Agrícola e Ambiental, v. 16, n. 7, p. 745-753, 2012.

ASSENHEIMER, A. Tratamento de dejeto bovino em sistema intensivo de produção de leite com aeração mecânica. 2007. 95p. Dissertação (Mestrado em agronomia) -
Universidade Estadual do Oeste do Paraná. 2007.

ABIPECS. Associação brasileira da indústria produtora e exportadora de carne suína 2013. Estatísticas. Disponível em: < http://www.abipecs.org.br/pt/estatisticas/mundi al/exportacao.html >. Acesso em: abr. 2014.

BELLAVER, C.; OLIVEIRA, P. Balanço da água nas cadeias de aves e suínos. 2009. Disponível em: <http://www.qualyfoco.com.br/arquivos_public acoes/arquivos/1266836613_Agua_essencial_v 2.pdf > Acesso em: nov. 2013.

BRASIL. 2006. Lei Federal $\mathbf{n}^{\mathbf{0}} \mathbf{1 1 . 3 2 6 / 0 6}$. Disponível em: <http://www.planalto.gov.br/ccivil_03/_Ato200 4-2006/2006/Lei/L11326.htm> Acesso em: jun. 2011.

CAMPOS, A.T. 2008. Tratamento de dejetos de bovinos de leite - Embrapa Gado de Leite. Disponível em: <http://www.cnpgl.embrapa.br/nova/sala/notici as/jornaldoleite.php?id=383> Acesso em: mar. 2011.

CAMPOS, A.T.; FEREIRA, W.A.; PACCOLA, A.A.; LUCAS JR, J.; ULBANERE, R.C.; CARDOSO, R.M.; CAMPOS, A.T. Tratamento biológico aeróbio e reciclagem de dejetos de bovinos em sistemas intensivos de produção de leite. Revista de Ciência e Agrotecnologia, v.26, n.2. p.426-438, 2002.

CAMPOS, A.T. Importância da água para bovinos de leite. Embrapa gado de Leite. (Comunicado técnico), 2000.

CCPR-MG. Manual de qualidade da água. Cooperativa Central dos Produtores Rurais de Minas Gerais, Belo Horizonte. 2004. 22p.

CONAMA - Conselho nacional do meio ambiente. Resolução no 357 , de 17 de março de 2005.

<http://www.mma.gov.br/port/conama/index.cf m> Acesso em: nov. 2013. 
CONAMA - Conselho nacional do meio ambiente. Resolução $n^{\circ} 375$, de 29 de agosto de 2006.

<http://www.mma.gov.br/port/conama/index.cf m > Acesso em: nov. 2013.

CONAMA - Conselho nacional do meio ambiente - Resolução no 396, de 03 de abril de 2008.

$<$ http://www.mma.gov.br/port/conama/index.cf m> Acesso em: nov. 2013.

CONAMA - Conselho nacional do meio ambiente.. Resolução $\mathbf{n}^{\mathbf{0}}$ 397, de 3 de abril de 2008.

<http://www.mma.gov.br/port/conama/index.cf m> Acesso em: nov. 2013.

CORRÊA, E.K.; CORRÊA, L.B.; COREZZOLLA, J.L.;BIANCHI, I. O impacto ambiental da suinocultura na ótica de produtores do oeste catarinense. Revista Brasileira de Agrociência, v.14, n.1, p.177-182, 2008.

DIAS, C.A.; BITENCOURT, M.I.P.; BEUX, S. Estimativa do desempenho das lagoas de estabilização em um laticínio. Synergismus Scyentifica, Pato Branco, v.1, n.2, p.25-30, 2006.

FRANÇA, C.G.; GROSSI, M.E.D.; MARQUES, V.P.M.A. O censo agropecuário 2006 e a agricultura familiar no Brasil. 2009. Disponível em: <http://www.economia.esalq.usp.br/intranet/upl oadfiles/121.pdf $>$ Acesso em: jun 2011.

FRICK, J.M. Estudo do monitoramento de efluentes líquidos industriais de frigoríficos no Rio Grande do Sul. 2011. 33p. Trabalho de conclusão de curso - monografia (Engenharia Química). Universidade Federal do Rio Grande do Sul. 2011.

FRONZA, N. Estudos da potencialidades do reuso de água de uma indústria frigorífica. 2004. 80p. Dissertação (mestrado - Engenharia de alimentos). Universidade Federal de Santa Catarina, 2004.
FURTADO, P.G. O Uso de biodigestores como opção rentável para o tratamento de dejetos de suínos. Fortaleza, 2007. Disponível em: <http://www.pecnordeste.com.br/pec2008/pecn ordeste/doc/suinocultura/Paulo\%20Guilherme \%20Furtado.pdf>. Acesso em: jul. 2008.

GEBLER, L.; PALHARES, J.C.P. (Eds.) Gestão ambiental na agropecuária. Brasília: Embrapa Informação Tecnológica. 2007. 310p.

GUERRA, M.G.; GALVÃO JÚNIOR, J.G.B.; RANGEL, A.H.N.; ARAÚJO, V.M.; GUILERMINO, M.M.; NOVAES, L.P. Disponibilidade e qualidade da água na produção de leite. Acta Veterinária Brasílica, v.5, n.3, p.230-235, 2011.

HERNANDES, J.F.M. Políticas públicas na gestão ambiental da suinocultura no Vale do Taquari - RS. 2010. 101p. Dissertação (mestrado em agronegócio) - Universidade Federal do Rio Grande do Sul, Porto Alegre. 2010.

JASPER, S.P. Analise econômica de dois sistemas naturais de tratamentos de água residuária na suinocultura. 2006. 81f. Dissertação (mestrado) - Universidade Estadual Paulista, Faculdade de Ciências Agronômicas, Botucatu, 2006.

KUNZ, A.; STEINENMETZ, R.L.R.; BORTOLI, M. Separação sólido-líquidos em efluentes da suinocultura. Revista Brasileira de Engenharia Agrícola e Ambiental, v.14, n.11, p.1220-1225, 2010.

KUNZ, A.; OLIVEIRA, P.A.V.; HIGARASHI, M.M.; SANGOI, V. Recomendação para uso de esterqueiras para armazenagem de dejetos de suínos. Comunicado Técnico. Ministério da Agropecuária e Abastecimento, 2004.

LAGGER, J.R.; MATA, H.T.; PECHIN, G.H. La importancia de la calidad del agua em producción lechera. Veterinaria Argentina, v.27, n.165, p.346-354, 2000. 
MAPA, 2011a. Mercado interno. Disponível em:

<http://www.agricultura.gov.br/animal/mercado -interno>. Acesso em: abr. 2011.

MAPA, 2011b. Suínos. Disponível em: <http://www.agricultura.gov.br/animal/especies /suínos.> Acesso em: abr. 2011.

MENEZES, J.F.S.; FREITAS, K.R; CAMO, M.L.do; SANTANA, R.O.; FREITASS, M.B.de.; PERES, L.C. Produtividade de massa seca de forrageiras adubadas com cama de frango e dejetos líquidos de suínos. I Simpósio Internacional sobre Gerenciamento de Resíduos de Animais. Uso dos Resíduos da Produção Animal como Fertilizante. 11 a 13 de Março de 2009 - Florianópolis, SC - Brasil.

MIRANDA, C. R. Avaliação de estratégias para a sustentabilidade da suinocultura. 2005. 264f. Tese (Doutorado em Engenharia Ambiental) - Programa de Pós-graduação em Engenharia Ambiental, Universidade Federal de Santa Catarina, Florianópolis. 2005.

OLIVEIRA, R.M. Biossistemas integrados na Suinocultura. Dossiê Técnico. Instituto Tecnológico do Paraná - TECPAR. 2006.

ORRICO, A.C.A.; LUCAS JÚNIOR, J.; ORRICO JÚNIOR, M.A.P. Caracterização e biodigestão anaeróbia dos dejetos de caprinos. Engenharia Agrícola, Jaboticabal, v.27, n.3, p.639-647, set./dez.2007.

PALHARES, J.C.P. Quantidade e qualidade da água na produção de suínos. Embrapa Suínos e Aves, 2010.

PAPADOPOULOS, I. Regional middle east and Europe Project on nitrogen fixation and water balance studies. IAEA, Viena, 1993. $65 \mathrm{p}$.

PERDOMO, C.C.; OLIVEIRA, P.A.V.; KUNZ, A. Metodologia sugerida para estimar o volume e a carga de poluentes gerados em uma granja de suínos. Concórdia: Embrapa CNPSA. 2003. 6p. (Comunicado Técnico).
PERDOMO, C.C.; LIMA, G.M. M.; NONES, K. Produção de Suínos e Meio Ambiente. In: $9^{\circ}$ Seminário Nacional de Desenvolvimento da Suinocultura. Anais... Gramados - RS. 2001.

PICININ, L.C.A. 2010. Quantidade e Qualidade da Água na Produção de Bovinos de Leite. Disponível em: < http://pt.engormix.com/MA-pecuarialeite/administracao/artigos/agua-producaobovinos-leite-t305/124-p0.htm.> Acesso em: nov. 2013.

POHLMANN, M.; FRANÇA, J.T.L.; ALVES, R.C.; OLIVEIRA, P.C.F. Lagoa aerada superficialmente: uma solução de baixo custo para o aumenta de eficiência. Hydra, p.28-33, 2009.

PORTUGAL, A.D. 2004. O Desafio da Agricultura Familiar. Disponível em: <http://www.embrapa.br/imprensa/artigos/2002 /artigo.2004-12-07.2590963189/> Acesso em: jul. 2011.

RANZI, T.J.D.; ANDRADE, M.A.N. Estudo de viabilidade de transformação de esterqueiras e bioesterqueiras para dejetos de suínos em biodigestores rurais visando o aproveitamento do biofertilizante e do biogás. In: Procedings of the 5th Encontro de Energia no Meio Rural, 2004, Campinas (SP)

RODRIGUES, A.M.; CECATO, U.; FUKUMOTO, N.M.; GALBEIRO, S.; SANTOS, G.T.; BARBEIRO, L.M. Concentrações e quantidades de macronutrientes na excreção de animais em pastagem de capim-mombaça fertilizada com fontes de fósforo. Revista Brasileira de Zootecnia, v.37, n.06, p.990-997, 2008.

SANTOS M.R.; MARTINEZ, M.A.; MATOS, A.A.; OLIVEIRA, R.A.; ZONTA, J.H.; Uso da reflectometria no domínio do tempo para avaliar a distribuição de fósforo em colunas de solos fertirrigados. Idesia, v. 30, n.1, p.45-53, 2012. 
SCHNEIDER, S. Teoria social, agricultura familiar e pluriatividade. Revista Brasileira de Ciências Sociais, v.18, n.51, p.99-122, 2003.

SCHEFFER-BASSO, S.M.; CHERER, C.V.; EUWANGER, M.F. Resposta de pastagens perenes à adubação com chorume suíno: pastagem natural. Revista Brasileira de Zootecnia, v. 37, n. 2, p.221-227, 2008.

SEGANFREDO, M.A. 2010. Os dejetos suínos e seus riscos ambientais no uso como fertilizante. Disponível em: < $<$ http://www.scielo.br/scielo.php?script=sci_nli nks\&ref $=000081 \&$ pid $=$ S 1413 -

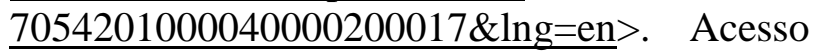
em: nov. 2013.

SERAFIM, R. S; GALBIATTI, J. A. Efeito da aplicação de água residuária de suinocultura na Brachiaria Brizantha cv marandu. Revista Colombiana Ciência Animal, v. 4, n. 1, p.185203, 2012.

SILVA, E.M.; ROSTON, D.M. Tratamento de efluentes de sala de ordenha de bovinocultura: Lagoas de estabilização seguidas de leito cultivado. Engenharia Agrícola, v.30, n.1, p.67-73, 2010.

SILVA, J.G.D. Fertirrigação do capim mombaça com diferentes lâminas de efluentes de tratamento primário de esgoto sanitário estabelecidas com base na dose aplicada de sódio. 2010. 64f. Dissertação (mestrado em Engenharia Agrícola). Universidade Federal de Viçosa. 2010.

SILVA, A.A. Viabilidade técnica e econômica da implantação da biodigestão anaeróbia e aplicação de biofertilizante nos atributos de solo e plantas. $2009.168 \mathrm{f}$. Tese (doutorado) Universidade Estadual Paulista, Faculdade de Ciências Agrárias e Veterinárias, 2009.

TAIZ, L.; ZEIGER, E. Fisiologia vegetal. 3.ed. Porto Alegre: Artmed, 2004, 613p.

VIANA, F.C. Qualidade da água: processos de captação e tratamento. Itambé: Cooperativa
Central de Minas Gerais, 2009. 12p. Manual Técnico. Disponível em: http://www.itambe.com.br/Cmi/Pagina.aspx?81 6. Acesso em 2009.

VILAS BÔAS, R.L.; SOUSA, T.R. Fertirrigação: uso e manejo. In: I SIMPAS - I Simpósio em sistemas agrosilvipastoris no semiárido. Resumos. Campina Grande - PB, 2008. 